\title{
Stock prices and economic activity nexus in OECD countries: new evidence from an asymmetric panel Granger causality test in the frequency domain
}

\author{
Veli Yilanci ${ }^{1}$, Onder Ozgur ${ }^{2 *}$ and Muhammed Sehid Gorus ${ }^{2}$
}

${ }^{*}$ Correspondence:

oozgur@ybu.edu.tr

${ }^{2}$ Ankara Yildirim Beyazit

Universitesi, Çubuk, Ankara,

Turkey

Full list of author information

is available at the end of the

article

\begin{abstract}
This study investigates the stock price-economic activity nexus in 12 member countries of the Organization for Economic Cooperation and Development (OECD) by employing monthly data over the period 1981:1-2018:3. For this purpose, the study uses Granger causality in the frequency domain in the panel setting by decomposing the symmetric and asymmetric fluctuations. This methodology determines whether the predictive power of interested variables is concentrated on quickly, moderately, or slowly fluctuating components. Our findings show that the stock prices have predictive power for future long-term economic activity in the panel setting. However, economic activity has more reliable information for stock prices for negative components. Additionally, empirical findings for asymmetric shocks are not fully consistent with those of symmetric ones. Besides, the country-specific results provide different causal linkages across members and frequencies. These findings may provide valuable information for policymakers to design proper and effective policies in OECD countries regarding the stock market and economic activity nexus.
\end{abstract}

Keywords: Asymmetric causality, Economic activity, Frequency domain, OECD countries, Panel data, Stock prices

JEL Classification: C32, E32, E44

\section{Introduction}

In recent years, a growing number of researchers and policymakers have attempted to clarify whether stock markets convey relevant information for future economic activity or vice versa. The very first discussions of the relationship between stock market prices and real economic activity emerged during the 1960s and 1970s with preliminary studies by Goldsmith (1969), Bosworth (1975), and Hall (1978).

The existing body of theoretical literature suggests that there are four main theories that explain the predictive performance of stock market prices for future economic growth: (1) discounted-cash-flow model; (2) wealth channel; (3) Tobin's Q channel; and (4) the financial accelerator theory. The first theory implies that a firm's current stock author(s) and the source, provide a link to the Creative Commons licence, and indicate if changes were made. The images or other third party material in this article are included in the article's Creative Commons licence, unless indicated otherwise in a credit line to the material. If material is not included in the article's Creative Commons licence and your intended use is not permitted by statutory regulation or exceeds the permitted use, you will need to obtain permission directly from the copyright holder. To view a copy of this licence, visit http:// creativecommons.org/licenses/by/4.0/. 
price is equal to the present discounted value of all future dividends. Because a firm's corporate earnings are directly related to industrial production, future payouts clearly reflect the future economic activity of a country (Fama 1990; Morck et al. 1990). If stock prices are related to fundamentals, they lead to real activity measures (Kim and In 2003). However, the vital role of forward-looking stock prices in forecasting the subsequent growth rates of real economic activity breaks down if stock market booms arise from speculative bubbles (Binswanger 2004).

The second theory suggests that stock prices could boost real economic activity through wealth channels related to the life-cycle hypothesis. Ando and Modigliani (1963) suggested that a substantial increase in stock prices would raise the wealth and permanent incomes of households. In this sense, the rise in permanent income increases demand and affects economic growth (Duca 2007).

The third theory is based on the Q theory of investment, which signals the link between stock prices and investment demand. The ratio of the market value of the capital stock to the replacement cost of capital is known as Tobin's $Q$, proposed by Tobin (1969). In this case, if the market values the new capital higher than its replacement cost, capital formation is triggered (Hassapis and Kalyvitis 2002). Consequently, an increase in stock prices compared to the replacement cost of capital would boost the $\mathrm{Q}$ value, and companies would increase investments because they would more likely expand production by investing in new physical capital (Mauro 2003).

The last theory is associated with the balance sheet strength of the firm. This theory is referred to as a financial accelerator by Bernanke and Gertler (1989) and focuses on the role of collateral value. High stock prices increase the collateral value of firms and provide positive information to the lender about the balance sheet strength of firms. This helps firms get loans with better conditions from lenders (Croux and Reusens 2013). In this case, firms expand their investment demand, and economic activity grows. Overall, while these theories offer a number of ideas, they all claim that stock prices could be a leading indicator of real economic activity. Nevertheless, there are also counter-arguments on the link between stock prices and economic activity having been broken.

Mauro (2003) argued that stock market prices do not have predictive power when stock market movements are not motivated by fundamentals. There are also a number of ideas that propose the weak effect of stock price performance on economic activity because of (a) expectations being subject to human error, creating misleading signals (Foresti 2006); (b) globally integrated stock markets possibly reducing saving rates and making domestic firms more dependent on foreign markets (Devereux and Smith 1994; Mao and Wu 2007); and (c) fluctuations in the real discount rate. It is common practice to perform a causality analysis to test the performance of stock market prices in explaining fluctuations in real economic activity (Mahdavi and Sohrabian 1991). On one hand, the causal relationship running from stock market prices to economic activity proposes that stock market indices do have reliable information to predict upcoming fluctuations in real economic indicators. Therefore, the stock market may be forward-looking for real economic activity (Croux and Reusens 2013). On the other hand, the causality running from economic activity to stock prices suggests that stock markets are prone to macroeconomic news, and financial activities are exacerbated by longer-term economic growth. (Tiwari et al. 2015). In other words, the significant causal link from economic activity 
to stock prices implies that movements in economic activity are a leading indicator of future stock market values (Liu and Sinclair 2008).

A considerable number of studies have attempted to investigate the stock price-economic activity nexus in both emerging and developed economies, albeit with contradictory results. No consensus has been reached about the direction of the causality, and whether stock prices have predictive power for future economic activity. In the empirical literature, the concept of Granger causality in the time domain has been used extensively to test the predictive power of stock prices. Conventional Granger causality tests calculate a single test statistic and cannot examine the causal relationship at various frequencies. At the same time, relatively few studies have employed the causality test in the frequency domain (e.g., Croux and Reusens 2013; Tiwari et al. 2015). Furthermore, previous studies do not distinguish between the causal impact of positive and negative shocks. Domian and Louton (1997), referring to Mitchell (1927) and Keynes (1936), stated that business cycle phases provide distinct asymmetries and argue the possible asymmetric linkage between industrial production growth and stock market returns. Koutmos (1999) also indicated that stock markets respond asymmetrically to past information. Hatemi-J (2019) argued that people react more heavily to negative news than positive news about financial markets. Wen et al. (2019) argued that stock price crash is a significant issue in the financial market and the main reason behind it is accumulated bad news. Similarly, Apergis and Miller (2006) stated that the consumption levels of people are more affected by negative news about finance. Therefore, it might be restrictive to assume that economic agents do not react asymmetrically under positive and negative shocks, especially in financial markets (Hatemi-J 2012). Thus, it is rational to consider asymmetric relationships among economic or financial variables. This study will go a step further and contribute to the existing literature by decomposing the symmetric and asymmetric causal relationship of the stock price-economic activity nexus in a panel setting and frequency domain. Employing Granger causality in the frequency domain by setting three domains determines whether the predictive power of interested variables is concentrated on quickly, moderately, or slowly fluctuating components. The strength and/or direction of the causality may differ in each frequency. Additionally, this study distinguishes between positive and negative shocks and aims to decompose their asymmetric causal relationship. To our knowledge, a causality analysis between stock prices and economic activity has not yet been conducted in the frequency domain by considering asymmetric components in the panel setting.

The primary aim of this paper is to explore the causal relationship between stock prices and economic activity in the frequency domain by considering asymmetries in 12 member countries of the Organization for Economic Cooperation and Development (OECD) - Austria, Finland, France, Germany, Ireland, Italy, Japan, Korea Republic, Netherlands, Sweden, the United Kingdom, and the United States. The study employs monthly data over the period 1981:1-2018:3. The historical data for both industrial production index (IPI) and stock price index (SPI) in OECD countries for the period examined are displayed in Figs. 1 and 2, respectively.

In the earlier years, the IPI was very low in Austria, Ireland, and the Korea Republic, while the index was higher in France, Italy, and the United Kingdom. Recently, Ireland has shown a remarkable performance considering industrial production reached 

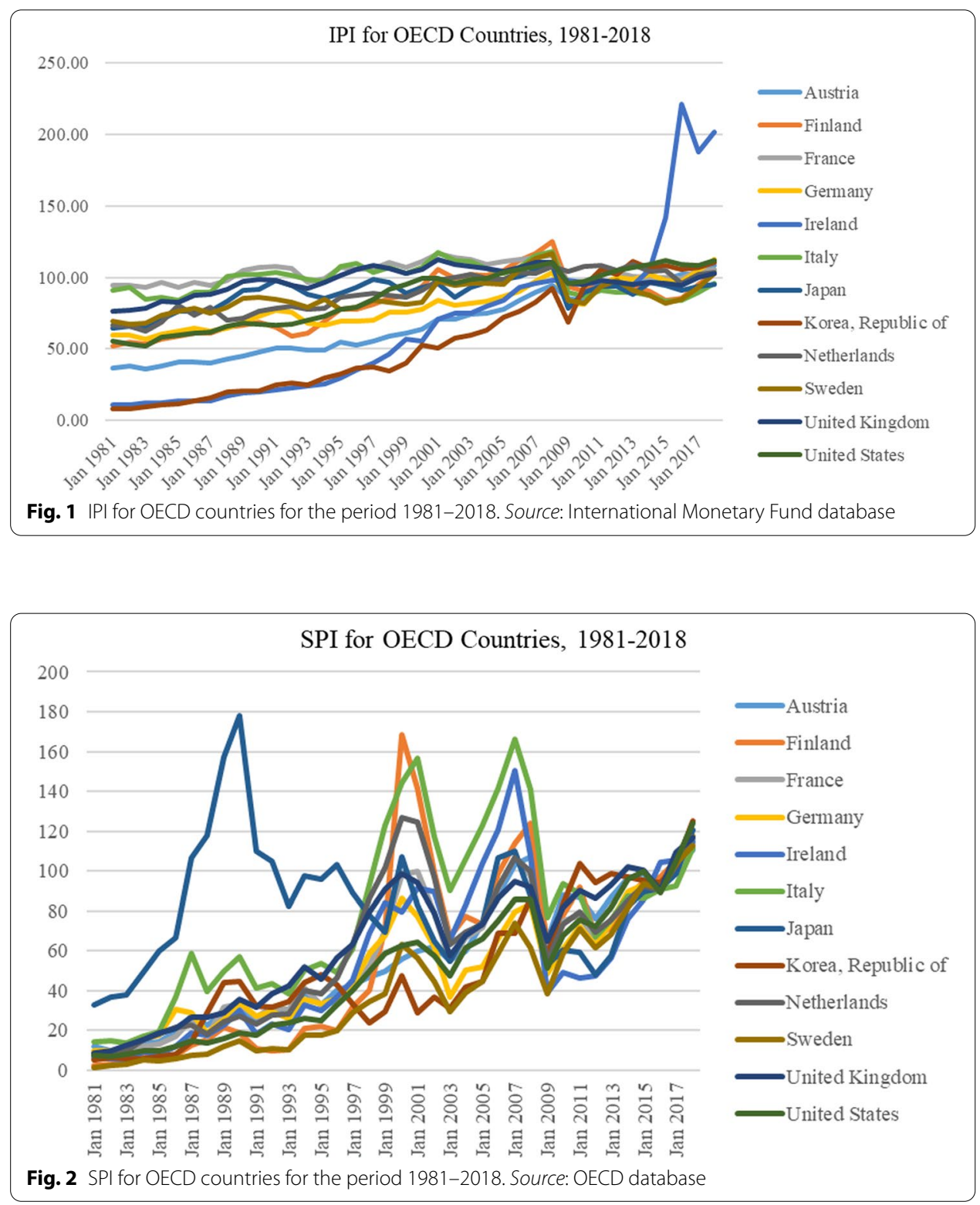

a 201.58 index value in January 2018. Additionally, Austria and the Korea Republic have also converged to the average of 12 countries with time. On the contrary, the remaining countries have shown positive, but relatively horizontal growth in production levels throughout the period examined.

Figure 2 displays the long-ranging data for the stock price index in 12 OECD countries for the period 1981 to 2018. Sweden and Finland had the lowest values at 1.41 and 2.40, respectively, while the Japanese economy had the highest value at 32.59 in 1981. Recently, all countries have reached similar values for stock price index (between 110 and 125) because of the high degree of capital mobility.

The empirical findings of this study indicate that stock prices have the predictive power for future economic activity in the long-term, while its causal impact is 
statistically insignificant in the remaining frequencies. However, economic activity has more reliable information for stock prices for negative components. In addition, the empirical results gathered from the asymmetric shocks are not fully consistent with those of symmetric ones.

The organization of the paper is as follows: "Literature review" section provides an overview of the existing literature. "Data and methodology" section introduces the data and methodology. "Empirical results" section presents the analyses and empirical results. "Policy implications" and "Conclusion" sections draw policy implications and conclude the study, respectively.

\section{Literature review}

More recently, there has been growing recognition of the causal links between stock market variables and economic activities in the literature. ${ }^{1}$ Stock market returns, stock market prices, stock market indices, stock market development, and stock market depth are commonly used as indicators to define stock market variables. Furthermore, real or nominal gross domestic product (GDP) is used to denote quarterly or annual economic activity. Studies using monthly samples employed the IPI as a proxy for real GDP measures.

The existing literature on the stock market economic activity nexus focusing on the United States is extensive. Lee (1992) conducted a pioneering study on the U.S. economy for the period 1947-1987, and concluded that the stock market properly signals real economic activity. In contrast, Binswanger (2000) suggested that the stock market failed to lead economic activity because of bubbles or fads during 1984-1995. Kim and In (2003) contributed to the literature by using a wavelet analysis and found a one-way causality running from the stock market to economic activities at the lower frequencies during 1959-2001. Additionally, Henry et al. (2010) highlighted a new methodology and proposed the multivariate asymmetric Generalized Autoregressive Conditional Heteroskedasticity (GARCH)-in-mean model. Their study focuses on business cycle phases and classified shocks as bad and good news. The most significant finding was that news about the economic activity is significant for stock market returns, and the magnitude of this effect differs depending on the phase of the business cycle. More recently, Ciner (2018) has employed time-varying causality analysis over the period between 1950 and 2017. The empirical findings of the study suggested that the stock market is not a reliable indicator of future economic activity.

A considerable amount of literature on the topic has been published on developed and/or developing countries as well (e.g., Caporale et al. 2004; Kaplan 2008; Liu and Sinclair 2008; Lyócsa et al. 2011; Pradhan et al. 2014, 2017; Tiwari et al. 2015; Tsouma 2009; Yang et al. 2018). First, Caporale et al. (2004) found significant evidence of unidirectional causality from stock market development to economic activity for Chile, Greece, Malaysia, and the Philippines, but found no causal connection for Argentina, Korea, and Portugal. By using various types of Granger causality tests in the time domain, Kaplan

${ }^{1}$ An overview of the literature review is presented in Table 1. 


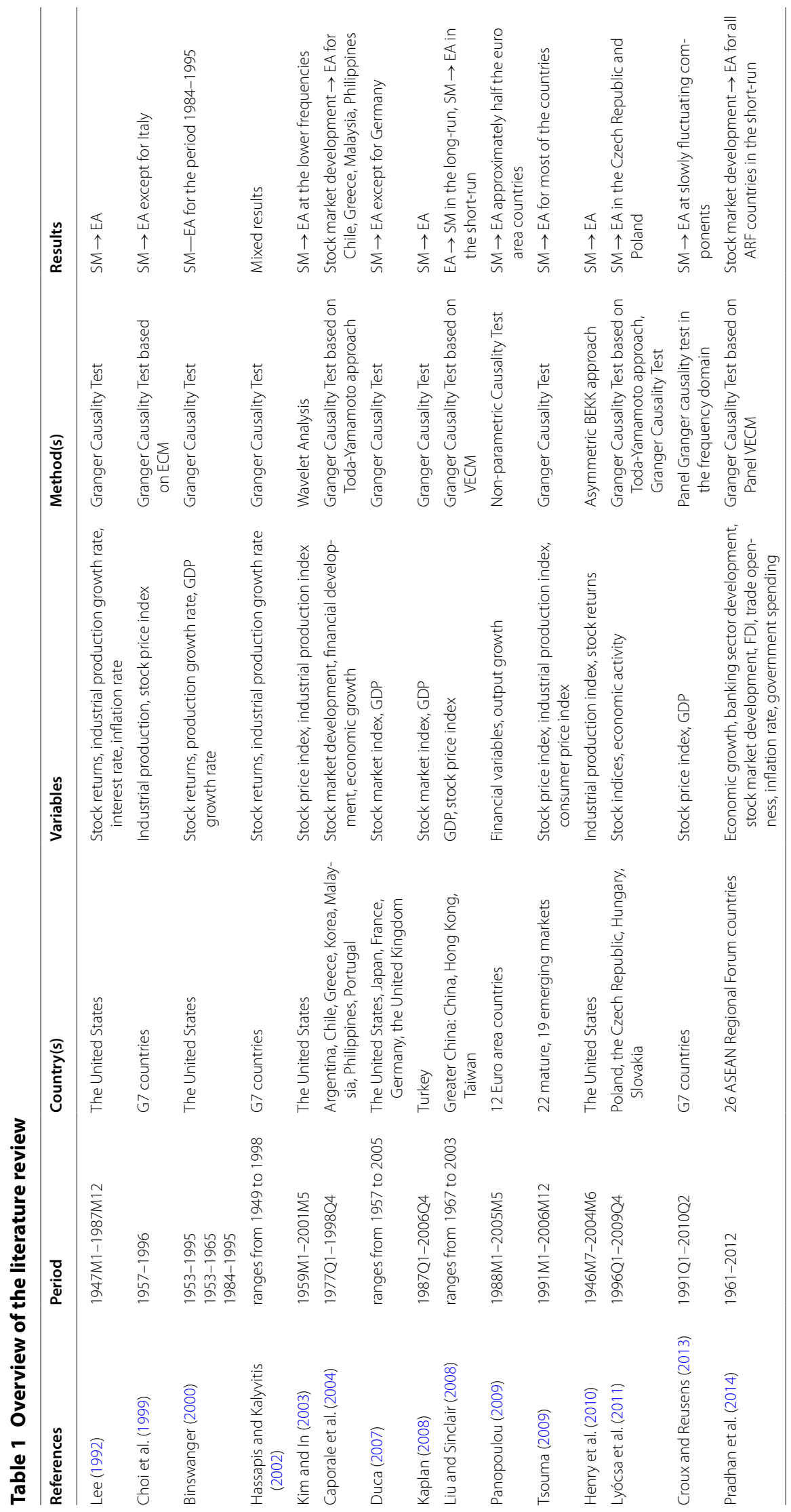




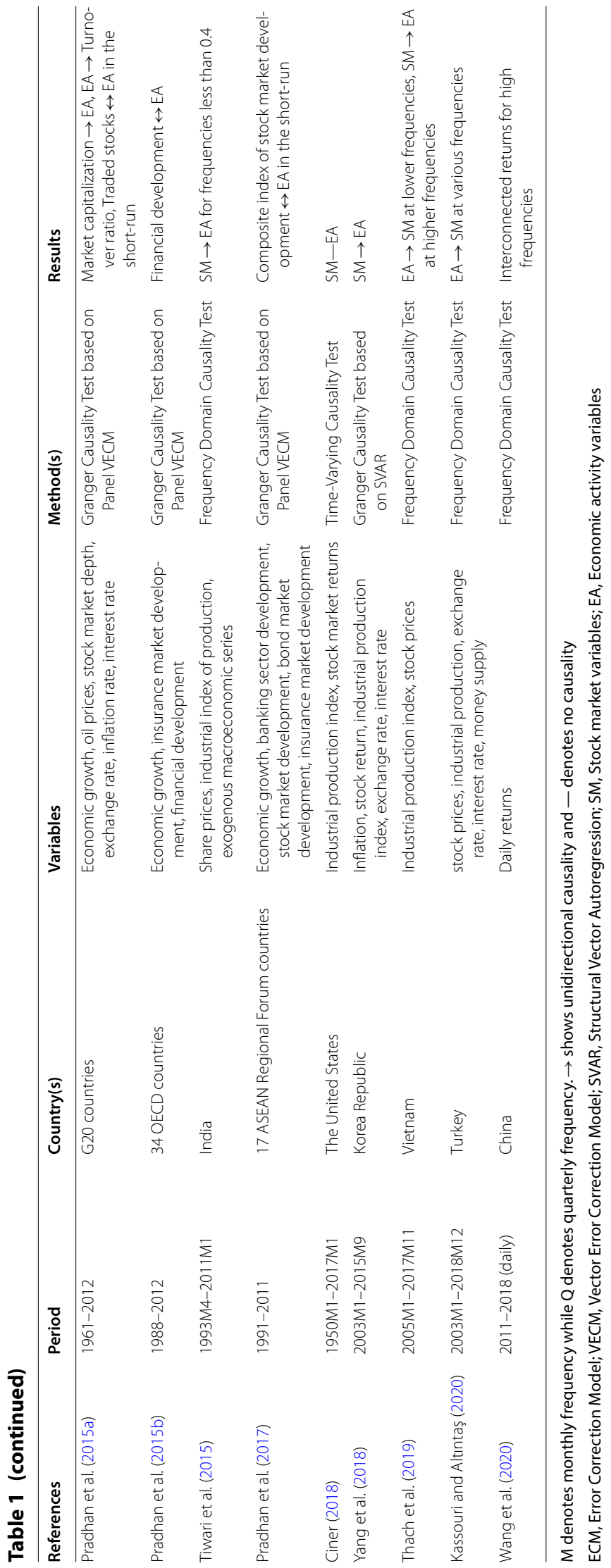


(2008) verified that the stock market has reliable information on future economic activity in Turkey, so did Liu and Sinclair (2008) for Greater China, ${ }^{2}$ Lyócsa et al. (2011) for the Czech Republic and Poland, Pradhan et al. (2014) for 26 member countries of the ASEAN Regional Forum (ARF), and Yang et al. (2018) for Korea. Of the studies concentrating on both developed and emerging economies, Tsouma (2009) examined the existing causal link for 22 mature and 19 emerging market economies using a monthly sample between 1991 and 2006. The empirical findings confirmed a one-way causality from stock price index to the IPI for most countries. Recently, Pradhan et al. (2017) has verified the bidirectional causality between the composite index of stock market development and economic activity for 17 ARF countries in the short run.

With regard to G7 countries, Choi et al. (1999) and Hassapis and Kalyvitis (2002) obtained mixed results on the causal relationship between stock market prices and economic activity in various countries. Pradhan et al. (2015a) investigated the relationship among economic growth, oil prices, stock market depth, exchange rate, inflation rate, and interest rate for G20 countries during 1961-2012. They found a unidirectional causality from market capitalization to economic activity, and from economic activity to turnover ratio in the short run. Moreover, traded stocks and economic activity were mutually determined in the short run. Duca (2007) found a one-way causal relationship from stock prices to economic activity for the United States, Japan, France, Germany, and the United Kingdom, and Panopoulou (2009) obtained the same finding for approximately half of the euro area countries. Lastly, Pradhan et al. (2015b) found a bidirectional causality between financial development and economic activity for 34 OECD countries.

A number of longitudinal empirical studies have reported that the stock market contains predictive power for further economic activities. However, more studies used the Granger causality in the time domain than in the frequency domain. Granger and Yoon (2002) discussed that if two or more time series variables respond to shocks together, they are cointegrated, however if the series only responds to a certain kind of shock, its components contain useful information about the dynamic nexus. The authors referred to the case where components have a long-run relationship as a hidden-cointegration.

Other studies also used the approach of Granger and Yoon (2002) to test the validity of different hypotheses. For instance, Hatemi-J (2011) suggested an asymmetric panel causality test, while Hatemi-J (2014) introduced asymmetric generalized impulse responses by decomposing the variables into positive and negative shocks. Yilanci and Aydin (2016) suggested the asymmetric bootstrap panel causality test by using this idea, while Hatemi-J et al. (2018) proposed a panel hidden-cointegration test. Bahmani-Oskooee et al. (2016) extended the causality test in the frequency-domain with negative and positive shocks and tested the causality link between the variables using the new asymmetric causality test in the frequency domain.

Among other studies dealing with the frequency domain, Croux and Reusens (2013) concentrated on the G7 countries in the panel setting, whereas Tiwari et al. (2015) focused on the Indian economy in the time series setting. Thach et al. (2019) investigated the causal link between the variables mentioned above for Vietnam covering the period 2005-2017.

${ }^{2}$ Greater China: China, Hong Kong, and Taiwan. 
Of the most recent studies, Kassouri and Altıntaş (2020) has analyzed the possible causal relationship between stock market prices and exchange rate at various frequencies in Turkey from January 2003 to December 2018. Their findings provide evidence that exchange rates, money supply, and interest rates have the predictive power to explain stock market fluctuations under different horizons. In another attempt, Wang et al. (2020) used the data for the daily returns of 30 Chinese financial institutions and concentrated on the interconnectedness of their returns in various frequencies. They found systemically connected returns for financial institutions in medium and high frequencies.

Although a few studies have recognized the causality analysis in the frequency domain, research has yet to systematically investigate the effects of asymmetric (positive and negative) shocks. To overcome this issue, this study extends Granger and Yoon's (2002) studydecomposing the variables into positive and negative cumulative shocks-to the panel causality analysis in the frequency domain.

\section{Data and methodology}

In this study, we test the causality relationship between the IPI and SPI for the 12 OECD countries. The availability of the monthly data restricts the scope of the countries in our analysis. The IPI series was employed for economic activity measure as a proxy for real GDP. The data in this study were drawn from two publicly open sources; the IPI series was taken from the International Monetary Fund (IMF) International Financial Statistics database, and the SPI series from the OECD database.

This study used a combined methodological approach based on Granger and Yoon (2002), and Croux and Reusens (2013). The frequency domain approach is superior to the wavelet analysis because it is simpler and handles stationary time series (see Croux and Reusens 2013). As stated by Dumitrescu and Hurlin (2012), if a causality relationship exists for a country, it is likely to be valid for other countries in many economic matters. So, the causality in the frequency domain using panel data can be tested more effectively since it enables us to use more observations than a single time series.

We first reviewed the methodology framework of the causality test in the frequency domain proposed by Breitung and Candelon (2006), since Croux and Reusens' (2013) panel causality test was based on it. To test the null hypothesis that no causality exists from the right to left hand variable, one can estimate the following equation:

$$
Y_{t}=\sum_{j=1}^{p} \Theta_{1, j} X_{t-j}+\sum_{j=1}^{p} \Theta_{2, j} Y_{t-j}+e_{1 t}
$$

where $\Theta_{1, j}$ and $\Theta_{2, j}$ show the coefficients of lag polynomials of $\Theta_{1}(L)$ and $\Theta_{2}(L)$, and $p$ indicates the optimal lag length. The null hypothesis can be expressed as:

$$
H_{0}: R(\omega) \Theta_{1}=0
$$

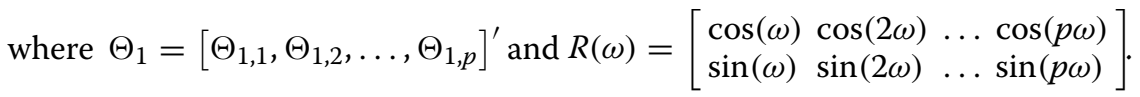

We can test the null hypothesis using F-test statistics that is distributed as $F(2, T-2 p)$ for $\omega \in(0, \pi)$.

To apply the panel Granger causality test in the frequency domain, we estimated the following seemingly unrelated equations using the feasible generalized least squares: 


$$
Y_{i, t}=\sum_{j=1}^{p} \beta_{i, j} X_{i, t-j}+\sum_{j=1}^{p} \gamma_{i, j} Y_{t-j}+\varepsilon_{i, t} \quad \text { for } \mathrm{i}=1,2,3, \ldots, \mathrm{N} .
$$

where $p$ and $N$ show the optimal lag length and number of countries in the panel, respectively. Because $\beta_{i, j}$ and $\gamma_{i, j}$ are specific countries, the heterogeneity captured across the countries is in the model. To test the null hypothesis that there is no causality running from $x_{t}$ to $y_{t}$ at frequency $\omega$, the following restrictions can be tested (Croux and Reusens 2013):

$$
\begin{array}{ll}
\sum_{j=1}^{p} \beta_{i, j} \cos (j \omega) & =0 \quad \text { for } i=1, \ldots, N \\
\sum_{j=1}^{p} \beta_{i, j} \sin (j \omega) & =0 \quad \text { for } i=1, \ldots, N
\end{array}
$$

The following F-test statistic can be used to test the null:

$$
F=\frac{\left(R^{2}-R_{*}^{2}\right) / 2 N}{\left(1-R^{2}\right) / N(T-2 p)}
$$

where $R^{2}$ and $R_{*}^{2}$ show the McElroy $\mathrm{R}$-squared values of the unrestricted and restricted seemingly unrelated regressions (SUR) models, respectively, and $2 N$ indicates the number of restrictions. The null can be rejected when $F>F_{\{2 N, N(T-2 p) ; 1-\alpha\}}$.

To consider asymmetry in the panel causality test in the frequency test, we used negative and positive cumulative shocks. To obtain the shocks, we decomposed the variables into the positive and negative shocks as follows:

$$
\begin{aligned}
& Y_{t}=Y_{0}+\sum_{i=1}^{t} e_{i}^{+}+\sum_{i=1}^{t} e_{i}^{-} \\
& X_{t}=X_{0}+\sum_{i=1}^{t} \varepsilon_{i}^{+}+\sum_{i=1}^{t} \varepsilon_{i}^{-}
\end{aligned}
$$

where $t=1,2, \ldots, T$ and $Y_{0}, X_{0}$ show the initial values for the associated variables; $e_{i}$ and $\varepsilon_{i}$ are white noise disturbance terms $e_{i}^{+}=\max \left(e_{i}, 0\right), \varepsilon_{i}^{+}=\max \left(\varepsilon_{i}, 0\right), e_{i}^{-}=\min \left(e_{i}, 0\right)$; and $\varepsilon_{i}^{-}=\min \left(\varepsilon_{i}, 0\right)$ shows the positive and negative shocks. Thus, the shocks of both variables can be defined as follows:

$$
Y_{t}^{+}=\sum_{i=1}^{t} e_{i}^{+}, Y_{t}^{-}=\sum_{i=1}^{t} e_{i}^{-}, X_{t}^{+}=\sum_{i=1}^{t} \varepsilon_{i}^{+} \text {and } X_{t}^{-}=\sum_{i=1}^{t} \varepsilon_{i}^{-}
$$

To consider asymmetry, or in other words apply the asymmetric panel Granger causality test in the Frequency domain, we can use these positive and negative shocks instead of the level of the variables in Eq. 2.

In the case of nonstationary variables, the differences of the series must be taken, to make them stationary. However, doing so can cause the loss of long-run information. Breitung and Candelon (2006) suggested that Toda-Yamamoto approach to the 
Table 2 Results of cross-sectional dependence tests for the panel unit root test equations

\begin{tabular}{llll}
\hline Variables & \multicolumn{2}{l}{ Test statistics } & \\
\cline { 2 - 4 } & LM test & CDLM test & CD test \\
\hline $\mathrm{SPI}$ & $18,678.020(0.000)^{*}$ & $1618.924(0.000)^{*}$ & $125.709(0.000)^{*}$ \\
$\mathrm{IPI}$ & $13,546.880(0.000)^{*}$ & $1172.315(0.000)^{*}$ & $109.400(0.000)^{*}$ \\
$\mathrm{SPI}^{-}$ & $28,502.880(0.000)^{*}$ & $2474.068(0.000)^{*}$ & $168.797(0.000)^{*}$ \\
$\mathrm{PPI}^{-}$ & $28,245.440(0.000)^{*}$ & $2451.661(0.000)^{*}$ & $168.014(0.000)^{*}$ \\
$\mathrm{SPI}^{+}$ & $28,660.200(0.000)^{*}$ & $2487.761(0.000)^{*}$ & $169.270(0.000)^{*}$ \\
$\mathrm{IPI}^{+}$ & $28,337.860(0.000)^{*}$ & $2459.705(0.000)^{*}$ & $168.297(0.000)^{*}$ \\
\hline
\end{tabular}

The numbers in the parentheses show the $p$ values

*The significance at the $1 \%$ level

causality analysis can be used for the frequency domain causality test in this case. Toda and Yamamoto (1995) suggested that in the case of nonstationary variables, a vector autoregressive model augmented with $d_{\max }$ is the highest order of integration of interested variables that can be estimated to test the causality relationship with the interested variables. Therefore, it is unnecessary to take the differences of the variables. In this lag augmented vector autoregressive model, only the significance of the first p lags must be tested, the augmented lags were not included in the testing. By following the approach of Toda and Yamamoto (1995), we augmented the vector autoregressive models with the maximum integration orders, so we do not need to take their differences.

\section{Empirical results}

As the first step in this study, the integration orders of the variables were evaluated by applying panel unit root tests. Before using the panel unit root test, the existence of cross-sectional dependence $(\mathrm{CD})$ must be tested across the panel members to ensure that we implement the appropriate type of unit root test.

We tested the null hypothesis of no $\mathrm{CD}$ across panel members by conducting three $\mathrm{CD}$ tests: the Lagrange multiplier (LM) test that Breusch and Pagan (1980) introduced, and the CD and CDLM tests that Pesaran (2004) introduced. ${ }^{3}$ If the null cannot be rejected, then first-generation panel unit root tests that ignore the cross-sectional dependency can be used. When the null is rejected, a second-generation panel unit root test must be utilized. The results of the CD tests are reported in Table 2.

According to the findings, there is strong evidence of cross-sectional dependency across the countries in the panel. We applied both Pesaran's (2007) panel unit root test (hereafter, CIPS), which is a cross-sectional augmented version of Im et al's (2003), and the panel stationarity test of Bahmani-Oskooee et al. (2014) (hereafter, BCW), which allows both smooth and sharp breaks via a Fourier function and dummy variables, and considers cross-sectional dependence. ${ }^{4}$ While we test the null hypothesis of the whole

\footnotetext{
${ }^{3}$ Please see the "Appendix 1-A" for details of the CD tests.

4 The explanation of Bahmani-Oskooee et al. (2014) panel unit root test is presented in the "Appendix 2".
} 
Table 3 Results of CIPS panel unit root test

\begin{tabular}{|c|c|c|c|c|}
\hline \multirow[t]{2}{*}{ Variables } & \multicolumn{2}{|l|}{ Level } & \multicolumn{2}{|c|}{ First differences } \\
\hline & Intercept & Intercept and trend & Intercept & Intercept and trend \\
\hline SPI & -1.611 & -2.347 & $-16.837^{*}$ & $-16.857^{*}$ \\
\hline IPI & -1.689 & -1.818 & $-4.875^{*}$ & $-5.060^{*}$ \\
\hline $\mathrm{SPI}^{-}$ & -0.398 & -1.240 & $-17.096^{*}$ & $-17.170^{*}$ \\
\hline$|\mathrm{P}|^{-}$ & 0.208 & -0.713 & $-6.730^{*}$ & $-7.869^{*}$ \\
\hline $\mathrm{SPI}^{+}$ & -0.979 & -0.987 & $-16.167^{*}$ & $-16.451^{*}$ \\
\hline$|\mathrm{P}|^{+}$ & 0.055 & -0.889 & $-5.925^{*}$ & $-7.111^{*}$ \\
\hline
\end{tabular}

Critical values for the CIPS panel unit root test with an intercept term at $10 \%, 5 \%$, and $1 \%$ levels are $-2.21,-2.32$, and -2.53 , and with an intercept and a trend term are $2.72,-2.83$, and -3.03 respectively

*The significance at the $1 \%$ level

Table 4 Results of cross-sectional dependence tests for the panel causality test equations

\begin{tabular}{lrrr}
\hline Direction of causality & \multicolumn{2}{l}{ Test statistics } & \\
\cline { 2 - 4 } & LM & \multicolumn{1}{c}{ CDLM } & \multicolumn{1}{c}{ CD } \\
\hline $\mathrm{SPI} \rightarrow \mathrm{PI}$ & $5636.207(0.000)^{*}$ & $484.824(0.000)^{*}$ & $61.299(0.000)^{*}$ \\
$\mathrm{IPI} \rightarrow \mathrm{SPI}$ & $12,542.326(0.000)^{*}$ & $1085.925(0.000)^{*}$ & $109.065(0.000)^{*}$ \\
$\mathrm{SPI}^{-} \rightarrow \mid \mathrm{PI}^{-}$ & $3975.032(0.000)^{*}$ & $340.238(0.000)^{*}$ & $53.743(0.000)^{*}$ \\
$\mid \mathrm{PI}^{-} \rightarrow \mathrm{SPI}^{-}$ & $13,676.079(0.000)^{*}$ & $1184.605(0.000)^{*}$ & $113.972(0.000)^{*}$ \\
$\mathrm{SPI}^{+} \rightarrow \mid \mathrm{PI}^{+}$ & $7151.657(0.000)^{*}$ & $616.727(0.000)^{*}$ & $74.396(0.000)^{*}$ \\
$|\mathrm{PI}|^{+} \rightarrow \mathrm{SPI}^{+}$ & $10,210.878(0.000)^{*}$ & $882.998(0.000)^{*}$ & $97.574(0.000)^{*}$ \\
\hline
\end{tabular}

The numbers in the parentheses show the $p$ values

*The significance at the $1 \%$ level

panel with a unit root in the CIPS test, the null of panel stationarity was tested in the BCW test. We tabulate the test results in Table 3.

The results of the CIPS test provided evidence that all variables (SPI, IPI, SPI ${ }^{+}, \mathrm{IPI}^{+}, \mathrm{SPI}^{-}$, and $\mathrm{IPI}^{-}$) in the analysis are stationary at the first differences. However, we reveal that all the series are stationary at the level when structural breaks are allowed, that is, the non-rejection of the null in the CIPS test is because of the structural breaks in the data generation process (see Perron 1989). Therefore, we used the series without taking their differences while testing the causality using the panel causality tests in the frequency domain.

Along with the panel unit root tests, panel cointegration and causality tests that ignore $\mathrm{CD}$ across the errors of individual equations and neglect slope heterogeneity, have low power in the case of dependence. Thus, prior to using the panel causality test in the frequency domain, this study tests the null hypothesis of cross-section independence in the panel causality equations to ensure that we employ appropriate causality tests. The results are tabulated in Table 4.

Based on the findings, the null of no-cross sectional dependency across the individual equations in the panel causality test is rejected because the $p$-values of the test statistics are smaller than the conventional significance tests. As Kónya (2006) stated, Zellner (1962)'s SUR method produces more efficient estimators than the ordinary least squares in this case. We can conduct the test using both the variables and the negative and positive components because the Croux and Reusens (2013) panel causality test in the frequency domain is based on the SUR estimators. The study employs the symmetric 
Table 5 Results of panel Granger causality test in the frequency domain

\begin{tabular}{|c|c|c|c|c|}
\hline \multirow[t]{2}{*}{ Direction of causality } & \multicolumn{4}{|c|}{ Test statistics } \\
\hline & $\omega=0.5$ & $\omega=1.5$ & $\omega=\mathbf{2 . 5}$ & CV \%10 \\
\hline $\mathrm{SPI} \rightarrow \mathrm{IPI}$ & $0.000244^{*}$ & 0.000106 & 0.000101 & 0.000135 \\
\hline $\mathrm{IPI} \rightarrow \mathrm{SPI}$ & $0.003067^{*}$ & $0.003555^{*}$ & $0.003688^{*}$ & 0.000814 \\
\hline $\mathrm{SPI}^{-} \rightarrow \mid \mathrm{PI}^{-}$ & $0.006947^{*}$ & 0.004033 & 0.004134 & 0.005858 \\
\hline $\mid \mathrm{PI}^{-} \rightarrow \mathrm{SPI}^{-}$ & $0.019851^{*}$ & $0.009812^{*}$ & $0.006930^{*}$ & 0.005538 \\
\hline $\mathrm{SPI}^{+} \rightarrow \mid \mathrm{PI}^{+}$ & $0.008334^{*}$ & 0.005551 & $0.006119^{*}$ & 0.005723 \\
\hline $\mid \mathrm{PI}^{+} \rightarrow \mathrm{SPI}^{+}$ & $0.011965^{*}$ & $0.007341^{*}$ & $0.009141^{*}$ & 0.005547 \\
\hline
\end{tabular}

*The existence of causality runs from the first variable to the second one

and asymmetric panel causality test in the frequency domain considering three different frequencies, $\omega=0.5, \omega=1.5$, and $\omega=2.5$, that correspond to the periodicities of 12.5 months, 4 months, and 2.5 months, respectively. ${ }^{5}$ By following the suggestions of Lütkepohl (1985) and Hacker and Hatemi-J (2008), we used Schwarz information criteria to select the optimal lag length. The results are displayed in Table 5 and Fig. 3 (see in the "Appendix 3").

A priori expectation for the predictive power of stock market prices for future economic activity is that the slowly fluctuating components of stock prices have more accurate information compared to quickly fluctuating components (Croux and Reusens 2013; Rua 2010). The results show that there is bidirectional causality between the SPI and IPI in the long term when the frequency is 0.5 . The significant causality running from the IPI to the stock price index suggests that macroeconomic news has reliable information for stock market prices, and that long-term economic growth may trigger stock market activities (Tiwari et al. 2015). Moreover, the existence of causality from the SPI to IPI denotes that the slowly fluctuating components of the stock market can be regarded as a leading indicator of long-term future economic activity. In this context, our results partly confirm the findings of Pradhan et al. (2015a, b), which exhibit bidirectional causality. However, there is only a one-way causality that runs from the IPI to the SPI in the medium and short terms. This means that the moderately and quickly fluctuating components of stock prices do not provide relevant information for future economic activity. In other words, stock prices do not have the predictive power for future economic activity in the medium and short terms. Hence, these results are not in line with prior expectations and do not provide evidence of the forward-looking behavior of stock markets.

For negative components, our empirical findings do not exhibit a causal relationship running from stock market prices to economic activity. However, there exists a causal relationship running from the negative components of the IPI to those of stock market prices, as is the case for the causal relationship running from the IPI to SPI. Therefore, the negative components of stock market prices do carry reliable information for the downturns of economic activity.

For positive components, our empirical findings do not provide any significant causal relationship between stock market prices and economic activity. In other words, the

${ }^{5}$ We define causality relationships at 0.5 (slowly fluctuating), 1.5 (moderately fluctuating), and 2.5 (quickly fluctuating) frequencies as long-term, intermediate-term, and short-term causalities, respectively. 
stock market does not boom, nor do economic upturns display significant predictive power for each other, and do not have a reliable information for its counterpart's future values. These findings apparently imply that negative cumulative shocks to economic activity have significantly greater predictive power on the future values of stock prices in all frequencies.

In general, this study shows that the forecasting ability of stock market prices is not significant for symmetric components. Stock market prices only exhibit a significant predictive power for symmetric values in the long term. In other words, stock market prices are reliable indicators for signaling sustainable economic growth. These findings might indicate the functioning of the wealth channel, Tobin's Q channel, and the financial accelerator theory, which were introduced in the Introduction. However, the study does not find the same case for the asymmetric components. Stock market booms and busts do not carry reliable information and therefore, are not good indicators of business cycles.

On the other hand, economic activity does have more predictive power for stock prices for all frequencies, except for positive components. This means that long-term economic growth can stimulate stock market activities and provide a sound financial system in OECD countries. This is also the case for negative cumulative shocks. This finding might indicate that economic downturns can damage stock market activities by reducing expected returns and decreasing cash-flows for firms. Given this context, we cannot conclude that economic agents would react differently to stock price and economic activity shocks.

This study also tests the null hypothesis of slope homogeneity ${ }^{6}$ in the panel causality equations and tabulate the results (Table 6). ${ }^{7}$

We reject the null of slope homogeneity according to the results of Delta and Delta adj tests. Therefore, by following Croux and Reusens (2013), we also provide the results for the asymmetric Granger causality test in the frequency domain with regards to the OECD countries in Table 7.

It is clear that the IPI has a predictive power for future values of stock market prices at the low frequencies. While the results in Table 5 indicate no-causality from $\mathrm{SPI}^{-}$to $\mathrm{IPI}^{-}$, and $\mathrm{SPI}^{+}$to $\mathrm{IPI}^{+}$at each selected frequencies, the above results indicate the rejection of the null hypothesis for both situations, at least in some of the countries. That is, we reject the null of $\mathrm{SPI}^{-} \nrightarrow \mathrm{IPI}^{-}$for Ireland and the Korea Republic, and the null of SPI $\nrightarrow \mathrm{IPI}^{+}$ for Austria, Ireland, Japan, and the Korea Republic at each selected frequencies, for Finland and Germany at both $\omega=1.5$ and $\omega=2.5$, and for Sweden only at $\omega=0.5$. Besides, $\mathrm{IPI}^{-}$Granger causes $\mathrm{SPI}^{-}$in Germany, the United Kingdom, and the United States at each selected frequency. In addition, a similar relationship is confirmed for Japan, Netherlands, and Sweden at both $\omega=1.5$ and $\omega=2.5$. The empirical results also demonstrate that the IPI ${ }^{+}$Granger only causes the $\mathrm{SPI}^{+}$in Austria for the period examined.

Overall, although the empirical findings of this study differ from those of published research considering the frequency domain analyses (Croux and Reusens 2013; Tiwari et al. 2015; Thach et al. 2019), they seem to be consistent with other research in the time domain, such as Pradhan et al. (2015a, b), which found bidirectional causality between

\footnotetext{
${ }^{6}$ Please see the "Appendix 1-B" for details about slope homogeneity tests.

7 Slope homogeneity test and country-specific Granger causality test results are included in the study upon the anonymous reviewer's suggestions.
} 
Table 6 Results of homogeneity tests

\begin{tabular}{lll}
\hline Direction of causality & \multicolumn{2}{l}{ Slope homogeneity test statistics } \\
\cline { 2 - 3 } & Delta test & Delta $_{\text {adj }}$ test \\
\hline $\mathrm{SPI} \rightarrow \mathrm{PI}$ & $364.450(0.000)^{*}$ & $365.676(0.000)^{*}$ \\
$\mathrm{PI} \rightarrow \mathrm{SPI}$ & $154.225(0.000)^{*}$ & $154.743(0.000)^{*}$ \\
$\left.\mathrm{SPI}\right|^{-} \rightarrow|\mathrm{PI}|^{-}$ & $718.723(0.000)^{*}$ & $721.141(0.000)^{*}$ \\
$|\mathrm{PI}|^{-} \rightarrow \mathrm{SPI}^{-}$ & $719.198(0.000)^{*}$ & $721.618(0.000)^{*}$ \\
$\left.\mathrm{SPI}\right|^{+} \rightarrow|\mathrm{PI}|^{+}$ & $747.445(0.000)^{*}$ & $749.960(0.000)^{*}$ \\
$|\mathrm{PI}|^{+} \rightarrow \mathrm{SPI}^{+}$ & $776.410(0.000)^{*}$ & $779.023(0.000)^{*}$ \\
\hline
\end{tabular}

The numbers in the parentheses show the $p$ values

*The significance at the $1 \%$ level

economic activities and stock prices. Of the studies considering frequency domain causality, Croux and Reusens (2013) found that stock market prices Granger cause economic activity in G7 countries in the long-term. Tiwari et al's (2015) findings also supported Croux and Reusens' (2013) results for the Indian economy in the long-term. Further, Thach et al. (2019) revealed that economic activity Granger causes stock prices in the long-term, while a reverse Granger causation is confirmed in the short-term for Vietnam. Similarly, Kassouri and Altıntaş (2020) provided favorable evidence that industrial production and financial variables (exchange rates, interest rates and money supply) have a significant predictive power for future values of stock market prices. Comparing our findings with those of Yacouba and Altintas (2019), which exhibit more significant results for the impact of exchange rate, interest rate and money supply on stock market returns in asymmetric components of these variables. These discrepancies could be attributed to differences in data, period, and sample examined. Moreover, it is hard to compare our remaining empirical results (asymmetric causality analyses) with the literature since this study is the first attempt to thoroughly examine the asymmetric causality between stock prices and economic activity in the frequency domain.

\section{Policy implications}

The empirical findings obtained from the panel causality analysis suggest several courses of action for policymakers in the long-run. First, stock prices and industrial production are mutually affected in the long term. Thus, policymakers should be careful when designing policies for financial markets and economic growth because of their interconnectedness. Second, stock prices provide valuable information for predicting future values of economic activity at slowly fluctuating components $(\omega=0.5)$. For this reason, policymakers should help provide a sound financial system to ensure long-run economic growth. Third, a broad recommendation is that they should provide a less volatile financial system because negative and positive components of stock prices lose their predictive power for future economic activity. Thus, more considerable efforts are needed to ensure a less volatile financial system since it might mitigate the uncertainty for estimating the future values of economic activity. Last, authorities should focus on output growth policies to strengthen financial markets given the significant predictive power of the IPI for stock prices. We have also learned that the IPI is a strong leading indicator for the stock market prices at quickly fluctuating components. Thus, policymakers may use 
Table 7 Results of asymmetric Granger causality test in the frequency domain

\begin{tabular}{|c|c|c|c|c|c|c|}
\hline \multirow[t]{2}{*}{ Countries/null hypotheses } & \multicolumn{3}{|c|}{$\mathrm{H}_{0}: \mathrm{SPI} \nrightarrow \mathrm{IPI}$} & \multicolumn{3}{|c|}{$\mathrm{H}_{0}: \mathrm{IPI} \nrightarrow \mathrm{SPI}$} \\
\hline & $\omega=0.5$ & $\omega=1.5$ & $\omega=2.5$ & $\omega=0.5$ & $\omega=1.5$ & $\omega=2.5$ \\
\hline Austria & 1.648 & 1.336 & 1.099 & $10.963^{*}$ & 0.983 & 0.593 \\
\hline Finland & $2.457^{* * *}$ & 1.354 & 0.779 & $4.629^{* *}$ & 0.777 & 0.809 \\
\hline France & 0.617 & 1.395 & 1.002 & $2.929 * * *$ & 0.345 & 0.260 \\
\hline Germany & 1.284 & 1.747 & 0.986 & $10.167^{*}$ & 1.755 & 1.224 \\
\hline Ireland & $21.005^{*}$ & $27.300^{*}$ & $27.628^{*}$ & $2.564^{* * *}$ & $2.496^{* * *}$ & $2.516^{* * *}$ \\
\hline Italy & 0.742 & 0.952 & 0.455 & $15.023^{*}$ & $2.388^{* * *}$ & 1.864 \\
\hline Japan & 0.469 & 0.555 & 1.082 & $4.441^{* *}$ & 1.844 & 1.619 \\
\hline Korea Republic & $6.721^{*}$ & $5.446^{*}$ & $4.398^{* *}$ & $2.940^{* * *}$ & $3.364^{* *}$ & $3.460^{* *}$ \\
\hline Netherlands & 0.702 & 1.027 & 0.908 & $7.997^{*}$ & 1.421 & 1.117 \\
\hline Sweden & 0.292 & 0.510 & 0.301 & 0.836 & 0.059 & 0.110 \\
\hline United Kingdom & 0.486 & 0.331 & 0.121 & $3.169^{* *}$ & 0.891 & 0.753 \\
\hline United States & $5.346^{*}$ & 0.220 & 0.029 & $8.976^{*}$ & $11.318^{*}$ & $11.673^{*}$ \\
\hline \multirow[t]{2}{*}{ Countries/null hypotheses } & \multicolumn{3}{|c|}{$\mathrm{H}_{0}: \mathrm{SPI}^{-} \nrightarrow \mathrm{IPI}^{-}$} & \multicolumn{3}{|c|}{$\mathrm{H}_{0}: \mathrm{IPI}^{-} \nrightarrow \mathrm{SPI}^{-}$} \\
\hline & $\omega=0.5$ & $\omega=1.5$ & $\omega=2.5$ & $\omega=0.5$ & $\omega=1.5$ & $\omega=2.5$ \\
\hline Austria & 0.933 & 0.932 & 0.932 & 0.134 & 0.186 & 0.188 \\
\hline Finland & 0.559 & 0.517 & 0.511 & 0.392 & 0.388 & 0.388 \\
\hline France & 0.420 & 0.455 & 0.462 & 1.848 & 1.343 & 1.300 \\
\hline Germany & 1.453 & 1.365 & 1.362 & $3.259^{* *}$ & $4.173^{* *}$ & $4.227^{* *}$ \\
\hline Ireland & $33.591^{*}$ & $20.942^{*}$ & $19.918^{*}$ & 0.033 & 0.529 & 0.589 \\
\hline Italy & 0.342 & 0.286 & 0.285 & 0.351 & 0.226 & 0.214 \\
\hline Japan & 1.377 & 1.076 & 1.085 & 1.635 & $2.340^{* * *}$ & $2.410^{* * *}$ \\
\hline Korea Republic & $14.104^{*}$ & $9.935^{*}$ & $9.572^{*}$ & 0.678 & 1.744 & 1.837 \\
\hline Netherlands & 0.473 & 0.490 & 0.491 & 2.229 & $2.321^{* * *}$ & $2.316^{* * *}$ \\
\hline Sweden & 1.044 & 1.140 & 1.149 & 1.672 & $2.965^{* * *}$ & $2.955^{* * *}$ \\
\hline United Kingdom & 0.867 & 0.999 & 1.015 & $6.029^{*}$ & $5.355^{*}$ & $5.293^{*}$ \\
\hline United States & 1.655 & 1.707 & 1.717 & $4.419^{* *}$ & $3.673^{* *}$ & $3.607^{* *}$ \\
\hline \multirow[t]{2}{*}{ Countries/null hypotheses } & \multicolumn{3}{|c|}{$\mathrm{H}_{0}: \mathrm{SPI}^{+} \nrightarrow \mathrm{IPI}^{+}$} & \multicolumn{3}{|c|}{$\mathrm{H}_{0}: \mathrm{IPI}^{+} \nrightarrow \mathrm{SPI}^{+}$} \\
\hline & $\omega=0.5$ & $\omega=1.5$ & $\omega=2.5$ & $\omega=0.5$ & $\omega=1.5$ & $\omega=2.5$ \\
\hline Austria & $3.652^{* *}$ & $4.368^{* *}$ & $4.437^{* *}$ & $3.749^{* *}$ & $3.643^{* *}$ & $3.640^{* *}$ \\
\hline Finland & 2.248 & $2.500^{* * *}$ & $2.508^{* * *}$ & 0.520 & 0.520 & 0.519 \\
\hline France & 1.494 & 0.625 & 0.567 & 0.922 & 0.772 & 0.775 \\
\hline Germany & 2.089 & $3.077^{* *}$ & $3.101^{* *}$ & 2.009 & 2.000 & 1.999 \\
\hline Ireland & $7.714^{*}$ & $6.102^{*}$ & $6.128^{*}$ & 0.552 & 0.320 & 0.323 \\
\hline Italy & 0.159 & 0.145 & 0.138 & 0.375 & 0.375 & 0.375 \\
\hline Japan & $2.756^{* * *}$ & $3.023^{* *}$ & $3.034^{* *}$ & 1.560 & 1.548 & 1.548 \\
\hline Korea Republic & $4.292^{* *}$ & $8.518^{*}$ & $8.890^{*}$ & 1.946 & 1.407 & 1.388 \\
\hline Netherlands & 0.569 & 0.593 & 0.589 & 0.480 & 0.487 & 0.487 \\
\hline Sweden & $2.522^{* * *}$ & 1.561 & 1.443 & 1.411 & 1.288 & 1.291 \\
\hline United Kingdom & 2.166 & 1.547 & 1.497 & 1.266 & 1.199 & 1.203 \\
\hline United States & 0.862 & 0.488 & 0.469 & 1.224 & 1.168 & 1.175 \\
\hline
\end{tabular}

${ }^{*}, * *,{ }^{* * *}$ The significance at the 1,5 , and $10 \%$ levels, respectively. Critical values are $2.315,3.016,4.654$ at the $10 \%, 5 \%, 1 \%$ levels, respectively

this information to develop targeted interventions aimed at improving financial development in the short-run.

The country-specific results obtained from the asymmetric Granger causality analysis in the frequency domain does not exhibit a consensus on the relationship between the 
stock price index and industrial production index. Thus, it is hard to carry out common economic policies regarding OECD countries; instead, they should follow national economic policies.

\section{Conclusion}

In the long term, which corresponds to 12.5 months, there is a bidirectional relationship between the stock price index and IPI regarding symmetric shocks. According to the findings, these variables are mutually determined and affected in the long term. Additionally, the IPI has predictive power for future values of stock market prices in negative components. Thus, an economic upsurge might be a good indicator of stock market busts. However, the insignificant causality from stock prices to economic activity in asymmetric components illustrate that stock market booms and busts are not an indicator of future economic activity. Furthermore, unidirectional causalities running from economic activity to stock prices were detected for both symmetric and negative components in all frequencies.

Overall, our results confirm that stock market prices provide a signal for the level of economic activity in the long-term. The significant predictive power of stock prices for sustainable economic activity can be explained by the validity of at least one of the following channels: (a) the wealth channel, (b) Tobin's Q channel, and (c) the balance sheet strength of firms. Additionally, the empirical results suggest that economic activities provide more relevant information for future stock market prices in our analysis. The findings reported here shed new light on the positive and negative cumulative shocks of the aforementioned variables.

Further study is required to better understand the possible causal link between economic activities and stock market returns regarding asymmetric cumulative shocks. For that purpose, various asymmetric Granger causality tests can be employed for both mature and emerging economies in the time series or panel data settings. The development in the econometric and statistical methods may minimize the bias of empirical findings. Thus, practitioners should focus on newer and better estimation techniques. Moreover, future studies can also target specific issues in the economic activity-stock prices nexus. They can examine the causal linkage in the sectoral basis to develop a deeper understanding of the relationships between economic activity and stock prices.

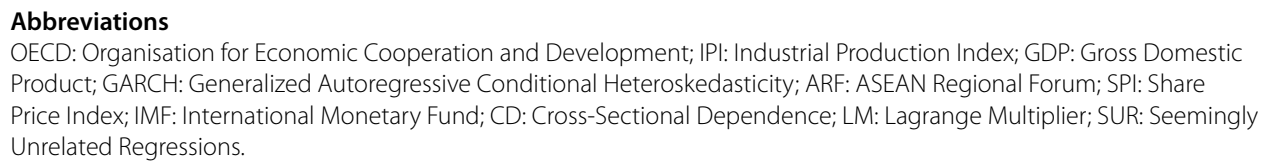

Acknowledgements

We are thankful to Mr. Peter Reusens for his kindly suggestions on this paper.

Authors' contributions

The authors have read and approved the final manuscript.

Funding

We do not receive any financial assistance from any agency.

Availability of data and materials

The datasets used and/or analyzed during the current study are available from the corresponding author on reasonable request.

Competing interests

The authors declare no competing interests. 
Author details

${ }^{1}$ Sakarya University, Serdivan, Sakarya, Turkey. ${ }^{2}$ Ankara Yildirim Beyazit Universitesi, Çubuk, Ankara, Turkey.

\section{Appendix 1: Cross-sectional dependence and delta homogeneity tests}

A. Cross-sectional dependence tests

Since ignoring the existence of cross-sectional dependence among the panel members may produce to biased results when using panel techniques, one should first use the cross-sectional dependence tests and test the null of non-existence of the dependence. The Lagrange-Multiplier test statistic, that is proposed by Breusch and Pagan (1989) can be computed using the following:

$$
L M=\sum_{i=1}^{N-1} \sum_{j=i+1}^{N} T_{i j} \hat{\rho}_{i j}^{2}
$$

where $\hat{\rho}_{i j}$ shows sample estimate of the correlation coefficient obtained from the residuals of related panel equations.

If the $\mathrm{N}$ is large relative to time period, $L M$ test statistic is not applicable. Pesaran (2004) suggested a scaled version of the test statistic as follows:

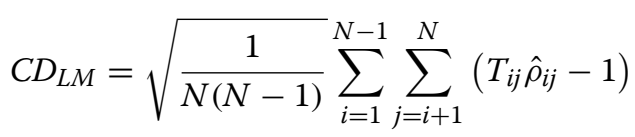

$C D_{L M}$ is distributed as $N(0,1)$ under the null. Since, both test statistics exhibit substantial size distortions, we can use the following test statistic that based on the average $\hat{\rho}_{i j} \mathrm{~s}$ and suggested by Pesaran (2004):

$$
C D=\sqrt{\frac{2}{N(N-1)}} \sum_{i=1}^{N-1} \sum_{j=i+1}^{N} T_{i j} \hat{\rho}_{i j}
$$

\section{B. Delta homogeneity tests}

By using the delta tests of Pesaran and Yamagata (2008) we can test the null hypothesis of slope homogeneity. The rejection of the null shows that the test equations of panel members have different slopes, and the panel tests should be used that allows this heterogeneity. We can compute the following test statistic for the null hypothesis:

$$
\tilde{\Delta}=\sqrt{N}\left(\frac{N^{-1} \tilde{S}-k}{\sqrt{2 k}}\right)
$$

where $\mathrm{N}$ shows the sample size, k indicates the number of right-hand variables, and $\tilde{S}$ is the Swamy test statistic. For small samples following adjusted delta test statistic can be employed: 


$$
\tilde{\Delta}_{a d j}=\sqrt{N}\left(\frac{N^{-1} \tilde{S}-k}{\sqrt{2 k(T-k-1) /(T+1)}}\right)
$$

\section{Appendix 2: Panel stationarity test with sharp and smooth breaks}

To consider possible smooth and sharp breaks in data generation process when testing the unit roots, we use the panel stationarity test of Bahmani-Oskooee et al. (2014). BahmaniOskooee et al. (2014) suggested to extend the panel stationarity test of Carrion-i-Silvestre et al. (2005) with a Fourier function so one does not need to predetermine the locations or numbers of break.

To test the stationarity of a panel series, the following equation is estimated:

$$
y_{i, t}=\alpha_{i}+\sum_{l=1}^{m_{i}} \theta_{i, l} D U_{i, l, t}+\gamma_{1, k} \sin \left(\frac{2 \pi k t}{T}\right)+\gamma_{2, k} \cos \left(\frac{2 \pi k t}{T}\right)+u_{i, t}
$$

where $m_{i}$ is number of sudden breaks. $D U$ indicates a dummy variable that captures the behavior of sharp changes and defined as follows:

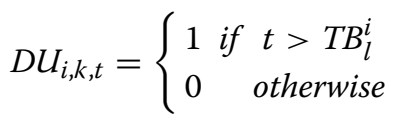

where $T B_{i}^{l}$ is the time of break for the $i$ th individual series. To allow also smooth breaks, we use the trigonometric terms where $k, t$ and $T$ indicate frequency, a time trend and number of observations, respectively. We determine the optimal value of $k$ by choosing the $\mathrm{k}$ in the interval $[1,2, \ldots, 5]$ which minimizes the sum of squares residuals. After selecting optimal k, we re-estimate Eq. 1 by using the optimal k, and determine the number and locations of the breaks by also choosing the $m$ that minimizes the SSR. To test the null hypothesis of stationarity, the following test statistic can be used:

$$
Z=\frac{\left(\sum_{i=1}^{N} L M_{i}-N \bar{\mu}_{L M}\right)^{0.5}}{\sigma_{L M}}
$$

where $\bar{\mu}_{L M}$ and $\sigma_{L M}$ represent the mean and standard deviation of LM. LM is the test statistic that computed for the $i$ th individual as follows:

$$
L M=\hat{\omega}_{i} T^{-2} \sum_{t=1}^{T} \hat{S}_{i t}^{2}
$$

Here, $\hat{S}_{i t}$ and $\hat{\omega}_{i}$ show the partial sum of the $u_{i, t}$ and a HAC estimator of the long run variance of $u_{i, t}$ respectively. Optimal critical values are obtained using bootstrap simulations.

\section{Appendix 3: The graphs of panel granger causality test in the frequency domain}

See Fig. 3. 


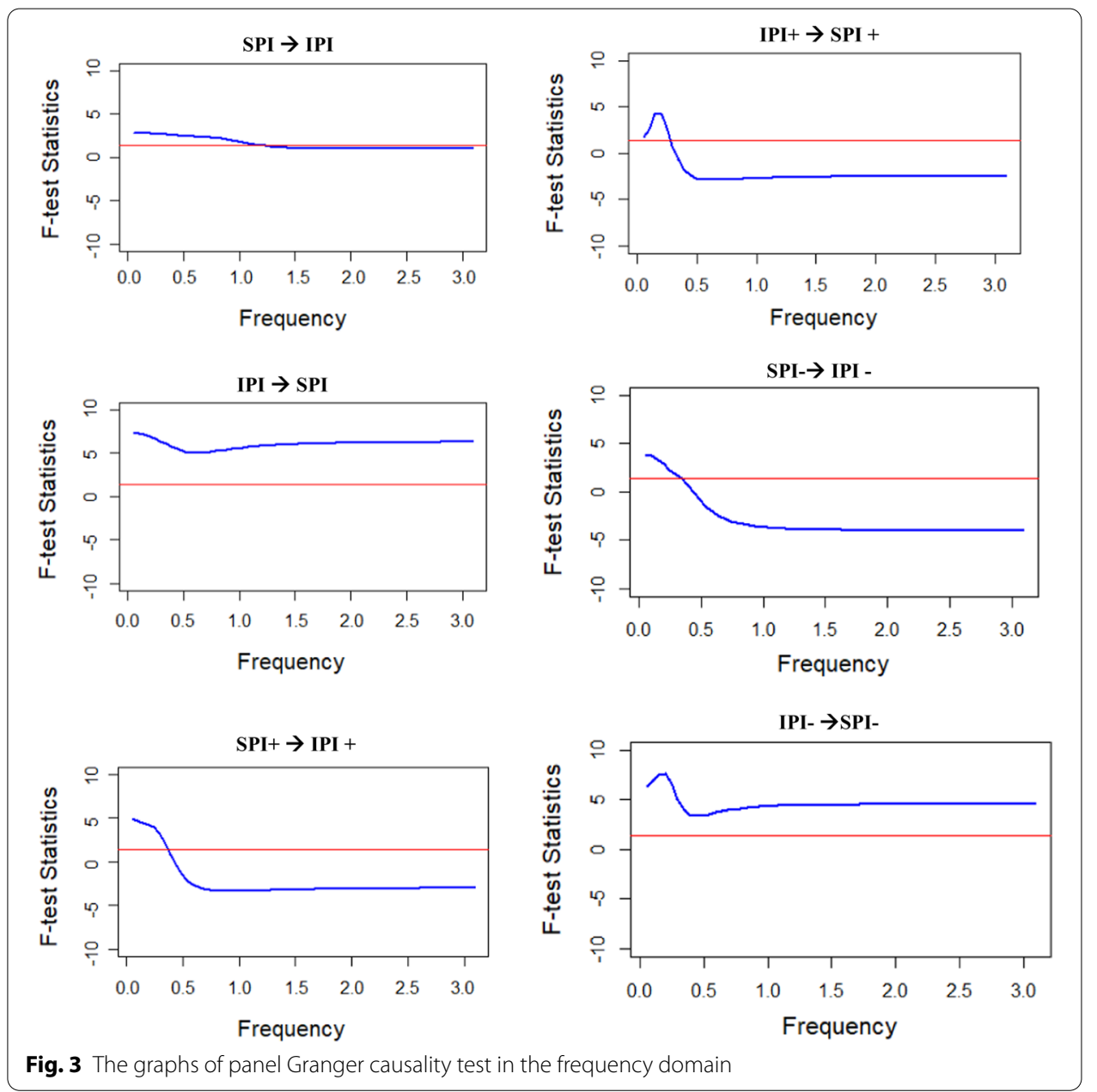

Received: 6 March 2020 Accepted: 11 December 2020

Published online: 05 February 2021

\section{References}

Ando A, Modigliani F (1963) The "life cycle'" hypothesis of saving: aggregate implications and tests. Am Econ Rev 53(1):55-84

Apergis N, Miller SM (2006) Consumption asymmetry and the stock market: empirical evidence. Econ Lett 93(3):337-342. https://doi.org/10.1016/j.econlet.2006.06.002

Bahmani-Oskooee M, Chang T, Wu T (2014) Revisiting purchasing power parity in African countries: panel stationary test with sharp and smooth breaks. Appl Financ Econ 24(22):1429-1438

Bahmani-Oskooee M, Chang T, Ranjbar O (2016) Asymmetric causality using frequency domain and time-frequency domain (wavelet) approaches. Econ Model 56:66-78

Bernanke B, Gertler M (1989) Agency costs, net worth and business fluctuations. Am Econ Rev 79(1):14-31

Binswanger M (2000) Stock returns and real activity: is there still a connection? Appl Financ Econ 10(4):379-387. https:// doi.org/10.1080/09603100050031507

Binswanger M (2004) Stock returns and real activity in the G-7 countries: Did the relationship change during the 1980s? Q Rev Econ Financ 44(2):237-252. https://doi.org/10.1016/j.gref.2003.07.001

Bosworth B (1975) The stock market and the economy. Brook Pap Econ Act 2:257-290

Breitung J, Candelon B (2006) Testing for short-and long-run causality: a frequency-domain approach. J Econ 132(2):363-378

Breusch TS, Pagan AR (1980) The Lagrange multiplier test and its applications to model specification in econometrics. Rev Econ Stud 47(1):239-253

Caporale GM, Howells PG, Soliman AM (2004) Stock market development and economic growth: the causal linkage. J Econ Dev 29(1):33-50 
Choi JJ, Hauser S, Kopecky KJ (1999) Does the stock market predict real activity? Time series evidence from the G-7 countries. J Bank Financ 23(12):1771-1792. https://doi.org/10.1016/S0378-4266(99)00020-5

Ciner C (2018) Does the stock market contain information about economic growth? Time-varying out of sample causality tests. Appl Econ Lett. https://doi.org/10.1080/13504851.2018.1540834

Croux C, Reusens P (2013) Do stock prices contain predictive power for the future economic activity? A Granger causality analysis in the frequency domain. J Macroecon 35:93-103. https://doi.org/10.1016/j.jmacro.2012.10.001

Devereux MB, Smith GW (1994) International risk sharing and economic growth. Int Econ Rev 35(3):535-550

Domian DL, Louton DA (1997) A threshold autoregressive analysis of stock returns and real economic activity. Int Rev Econ Financ 6(2):167-179

Duca G (2007) The relationship between the stock market and the economy: experience from international financial markets. Bank Valletta Rev 36(3):1-12

Dumitrescu El, Hurlin C (2012) Testing for Granger non-causality in heterogeneous panels. Econ Model 29(4):1450-1460

Fama EF (1990) Stock returns, expected returns, and real activity. J Financ 45(4):1089-1108. https://doi. org/10.1111/j.1540-6261.1990.tb02428.x

Foresti P (2006) Testing for granger causality between stock prices and economic growth. Munich Personal RePec Archive (MPRA), 62. http://mpra.ub.uni-muenchen.de/2962

Goldsmith RW (1969) Financial structure and development. Yale University Press, New Haven

Granger CW, Yoon G (2002) Hidden cointegration. Department of Economics Working Paper. University of California, San Diego

Hacker RS, Hatemi-J A (2008) Optimal lag-length choice in stable and unstable VAR models under situations of homoscedasticity and ARCH. J Appl Stat 35(6):601-615. https://doi.org/10.1080/02664760801920473

Hall R (1978) Stochastic implications of the life cycle-permanent income hypothesis: theory and evidence. J Polit Econ 86:971-987

Hassapis C, Kalyvitis S (2002) Investigating the links between growth and real stock price changes with empirical evidence from the G-7 economies. Q Rev Econ Financ 42(3):543-575. https://doi.org/10.1016/S1062-9769(01)00111-9

Hatemi-J A (2011) Asymmetric panel causality tests with an application to the impact of fiscal policy on economic performance in Scandinavia. University Library of Munich, Germany

Hatemi-J A (2012) Asymmetric causality tests with an application. Emp Econ 43(1):447-456. https://doi.org/10.1007/ s00181-011-0484-x

Hatemi-J A (2014) Asymmetric generalized impulse responses with an application in finance. Econ Model 36:18-22

Hatemi-J A (2019) The causal impact of stock market development on economic development in the UAE: an asymmetric approach. Inter Econ 72(2):171-184

Hatemi-J A, Chang T, Chen WY, Lin FL, Gupta R (2018) Asymmetric causality between military expenditures and economic growth in top six defense spenders. Qual Quant 52(3):1193-1207

Henry Ó, Olekalns N, Shields K (2010) Sign and phase asymmetry: news, economic activity and the stock market. J Macroecon 32(4):1083-1100. https://doi.org/10.1016/j.jmacro.2010.06.006

Im KS, Pesaran MH, Shin Y (2003) Testing for unit roots in heterogeneous panels. J Econ 115(1):53-74. https://doi. org/10.1016/S0304-4076(03)00092-7

Kaplan M (2008) The impact of stock market on real economic activity: evidence from Turkey. J Appl Sci 8(2):374-378

Kassouri Y, Altıntaş H (2020) Threshold cointegration, nonlinearity, and frequency domain causality relationship between stock price and Turkish Lira. Res Bus Financ 52:101097

Keynes JM (1936) The general theory of employment, interest and money. MacMillan, London

Kim S, In FH (2003) The relationship between financial variables and real economic activity: evidence from spectral and wavelet analyses. Stud Nonlinear Dyn Econ 7(4):1-16. https://doi.org/10.2202/1558-3708.1183

Kónya L (2006) Exports and growth: granger causality analysis on OECD countries with a panel data approach. Econ Model 23(6):978-992. https://doi.org/10.1016/j.econmod.2006.04.008

Koutmos G (1999) Asymmetric price and volatility adjustments in emerging Asian stock markets. J Bus Financ Acc 26(1-2):83-101

Lee BS (1992) Causal relations among stock returns, interest rates, real activity, and inflation. J Financ 47(4):1591-1603. https://doi.org/10.1111/j.1540-6261.1992.tb04673.x

Liu X, Sinclair P (2008) Does the linkage between stock market performance and economic growth vary across Greater China? Appl Econ Lett 15(7):505-508. https://doi.org/10.1080/13504850500426277

Lütkepohl H (1985) Comparison of criteria for estimating the order of a vector autoregressive process. J Time Ser Anal 6(1):35-52. https://doi.org/10.1111/j.1467-9892.1985.tb00396.x

Lyócsa Š, Baumöhl E, Výrost T (2011) The stock markets and real economic activity: new evidence from CEE. East Eur Econ 49(4):6-23. https://doi.org/10.2753/EEE0012-8775490401

Mahdavi S, Sohrabian A (1991) The link between the rate of growth of stock prices and the rate of growth of GNP in the United States: a Granger causality test. Am Econ 35(2):41-48. https://doi.org/10.1177/056943459103500206

Mao Y, Wu R (2007) Does the stock market act as a signal for real activity? Evidence from Australia. Econ Pap J Appl Econ Policy 26(2):180-192. https://doi.org/10.1111/j.1759-3441.2007.tb01015.x

Mauro P (2003) Stock returns and output growth in emerging and advanced economies. J Dev Econ 71(1):129-153. https ://doi.org/10.1016/S0304-3878(02)00136-0

Mitchell W (1927) Business cycles: the problem and its setting. NBER, New York

Morck R, Shleifer A, Vishny RW, Shapiro M, Poterba JM (1990) The stock market and investment: Is the market a sideshow? Brook Pap Econ Act 2:157-215

Panopoulou E (2009) Financial variables and euro area growth: a non-parametric causality analysis. Econ Model 26(6):1414-1419. https://doi.org/10.1016/j.econmod.2009.07.013

Pesaran MH (2004) General diagnostic tests for cross section dependence in panels. Cambridge Working Papers in Economics (No. 0435), University of Cambridge, Faculty of Economics

Pesaran MH (2007) A simple panel unit root test in the presence of cross-section dependence. J Appl Econ 22(2):265312. https://doi.org/10.1002/jae.951 
Pesaran MH, Yamagata T (2008) Testing slope homogeneity in large panels. J Econ 142(1):50-93

Pradhan RP, Arvin MB, Ghoshray A (2015a) The dynamics of economic growth, oil prices, stock market depth, and other macroeconomic variables: evidence from the G-20 countries. Int Rev Financ Anal 39:84-95. https://doi. org/10.1016/j.irfa.2015.03.006

Pradhan RP, Arvin MB, Norman NR (2015b) Insurance development and the finance-growth nexus: evidence from 34 OECD countries. J Multinatl Financ Manag 31:1-22. https://doi.org/10.1016/j.mulfin.2015.02.001

Pradhan RP, Arvin MB, Bahmani S, Hall JH, Norman NR (2017) Finance and growth: evidence from the ARF countries. Q Rev Econ Financ 66:136-148. https://doi.org/10.1016/j.qref.2017.01.011

Pradhan RP, Arvin MB, Hall JH, Bahmani S (2014) Causal nexus between economic growth, banking sector development, stock market development, and other macroeconomic variables: the case of ASEAN countries. Rev Financ Econ 23(4):155-173. https://doi.org/10.1016/..rfe.2014.07.002

Rua A (2010) Measuring comovement in the time-frequency space. J Macroecon 32(2):685-691. https://doi. org/10.1016/j.jmacro.2009.12.005

Thach NN, Anh LH, Phuong HTN (2019) Frequency domain causality analysis of stock market and economic activities in Vietnam. In: Kreinovich V, Sriboonchitta S (eds) Structural changes and their econometric modeling. TES 2019. Studies in computational intelligence, vol 808. Springer, Cham. https://doi.org/10.1007/978-3-030-04263-9_49

Tiwari AK, Mutascu MI, Albulescu CT, Kyophilavong P (2015) Frequency domain causality analysis of stock market and economic activity in India. Int Rev Econ Financ 39:224-238. https://doi.org/10.1016/j.iref.2015.04.007

Tobin J (1969) A general equilibrium approach to monetary theory. J Money Credit Bank 1(1):15-29

Toda HY, Yamamoto T (1995) Statistical inference in vector autoregressions with possibly integrated processes. J Econ 66(1-2):225-250

Tsouma E (2009) Stock returns and economic activity in mature and emerging markets. Q Rev Econ Financ 49(2):668685. https://doi.org/10.1016/j.qref.2008.02.002

Wang GJ, Si HB, Chen YY, Xie C, Chevallier J (2020) Time domain and frequency domain Granger causality networks: application to China's financial institutions. Financ Res Lett. https://doi.org/10.1016/j.frl.2020.101662

Wen F, Xu L, Ouyang G, Kou G (2019) Retail investor attention and stock price crash risk: evidence from China. Int Rev Financ Anal 65:101376

Yacouba K, Altintas H (2019) The asymmetric impact of macroeconomic shocks on stock returns in Turkey: a nonlinear ARDL approach. J Econ Forecast 22:98-116

Yang E, Kim SH, Kim MH, Ryu D (2018) Macroeconomic shocks and stock market returns: the case of Korea. Appl Econ 50(7):757-773. https://doi.org/10.1080/00036846.2017.1340574

Yilanci V, Aydin M (2016) Oil prices and stock prices: an asymmetric panel causality approach. J Appl Res Financ Econ 2(4):9-19

Zellner A (1962) An efficient method of estimating seemingly unrelated regressions and tests for aggregation bias. J Am Stat Assoc 57(298):348-368

\section{Publisher's Note}

Springer Nature remains neutral with regard to jurisdictional claims in published maps and institutional affiliations.

\section{Submit your manuscript to a SpringerOpen ${ }^{\circ}$ journal and benefit from:}

- Convenient online submission

- Rigorous peer review

- Open access: articles freely available online

- High visibility within the field

- Retaining the copyright to your article

Submit your next manuscript at $\mathbf{s p r i n g e r o p e n . c o m ~}$ 